\title{
Combined bronchoalveolar lavage and transbronchial lung biopsy: safety and yield in ventilated patients
}

\author{
P.A. Bulpa*, A.M. Dive*, L. Mertens*, M.A. Delos ${ }^{\#}$, J. Jamart ${ }^{\top}$, P.A. Evrard*, M.R. Gonzalez*, \\ E.J. Installé*
}

Combined bronchoalveolar lavage and transbronchial lung biopsy: safety and yield in ventilated patients. P.A. Bulpa, A.M. Dive, L. Mertens, M.A. Delos, J. Jamart, P.A. Evrard, M.R. Gonzalez, E.J. Installé. (C) ERS Journals Ltd 2003.

ABSTRACT: The aim of this study was to evaluate the safety and diagnostic yield of bedside bronchoalveolar lavage (BAL) combined with fibrescopic transbronchial lung biopsy (TBLB) in determining the aetiology of pulmonary infiltrates in mechanically ventilated patients.

The records of 38 mechanically ventilated patients who underwent BAL/TBLB to investigate unexplained pulmonary infiltrates were retrospectively reviewed. Patients were divided into two groups: immunocompetent (group 1: $n=22$; group 1a: $n=11$, late acute respiratory distress syndrome (ARDS); group 1b: $n=11$, no ARDS) and immunocompromised (group 2, $\mathrm{n}=16$ ).

The procedure allowed a diagnosis in 28 patients $(74 \%)$, inducing therapeutic modification in $24(63 \%)$ and confirmation of clinical diagnosis in four $(11 \%)$. In groups 1a, $1 \mathrm{~b}$ and 2, diagnosis was obtained in 11 out of 11 (fibroproliferation), seven out of 11 and 10 out of 16 patients, and therapy changed in 11 out of 11 (administration of steroids), six out of 11 and seven out of 16 patients, respectively. Pneumothorax occurred in nine patients (four of group 1a), bleeding in four $(<35 \mathrm{~mL})$, and transient hypotension in two. No fatalities were procedure-related.

Combined bronchoalveolar lavage/transbronchial lung biopsy is of diagnostic and therapeutic value in mechanically ventilated patients with unexplained pulmonary infiltrates, excluding those with late acute respiratory distress syndrome. Although complications are to be expected, the benefits of the procedure appear to exceed the risks in patients in whom a histological diagnosis is deemed necessary.

Eur Respir J 2003; 21: 489-494.
Depts of *Intensive Care, ${ }^{\#}$ Pathology and Biostatistics, Mont-Godinne University Hospital, Université Catholique de Louvain, Yvoir, Belgium.

Correspondence: P.A. Bulpa

Dept of Intensive Care

Mont-Godinne University Hospital

Université Catholique de Louvain

5530 Yvoir

Belgium

Fax: 3281423862

E-mail: pierre.bulpa@rean.ucl.ac.be

Keywords: Bronchoalveolar lavage diagnostic tool

mechanically ventilated patients transbronchial lung biopsy

Received: November 272001 Accepted after revision: October 22 2002
Pulmonary infiltrates are often encountered in mechanically ventilated patients and represent a challenge for intensivists. The aetiology is often multivariate and empiric therapy is frequently initiated on the basis of clinical diagnosis, which is of uncertain accuracy. This approach can lead to inappropriate treatment with the ensuing risks of possible adverse events, while potentially reversible causes may go unrecognised.

There are few diagnostic tools available to investigate pulmonary infiltrates in mechanically ventilated patients as: 1) thoracic imaging differentiates pulmonary infiltrates with difficulty; 2) bronchoalveolar lavage (BAL) or protected specimen brush give good microbiological yields [1] but provide no histological information; and 3) open lung biopsy (OLB) offers good diagnostic yields for infection and other diagnoses [2-6], but physicians are reluctant to perform this operation in these patients.

Some authors have suggested using transbronchial lung biopsies (TBLB) instead of OLB [7]. However, physicians are still unwilling to perform TBLB in ventilated patients despite encouraging preliminary results $[8,9]$ suggesting that, at least from a histological point of view, its diagnostic yield could be as high as OLB with fewer complications [10].

As combining BAL and TBLB in one procedure can provide both microbiological and histological information

For editorial comments see page 383.
$[8,9]$, the authors have systematically performed combined BAL/TBLB instead of open lung biopsy since June 1996 with mechanically ventilated patients in whom this surgical procedure is considered necessary to diagnose otherwise unexplained pulmonary infiltrates. The authors report their experience of the feasibility, safety and efficacy of this procedure in this population of patients.

\section{Materials and methods}

\section{Study population}

All mechanically ventilated patients with pulmonary infiltrate(s) who underwent combined BAL/TBLB between June 1996 and the end of February 2000 were evaluated. The authors proceeded to use BAL/TBLB when a diagnosis could not be obtained by usual noninvasive methods, including thoracic imaging and cultures (e.g. sputum, endotracheal aspirate), and when lung tissue samples could optimise therapy. Exclusion criteria were: 1) severe coagulopathy (platelet count $<50,000$ thrombocytes $\cdot \mathrm{mm}^{-3}$ despite platelet transfusion, fibrinogen $\leqslant 150 \mathrm{mg} \cdot \mathrm{dL}$, activated partial thromboplastin time (aPTT) $\geqslant 50 \mathrm{~s}$, or prothrombin time $\leqslant 50 \%$ ); and 2) haemodynamic instability (mean arterial 
pressure (MAP) $<60 \mathrm{mmHg}$ despite a continuous infusion of norepinephrine).

\section{Procedure}

Combined BAL/TBLB was performed at the bedside by the same physician (P.A. Bulpa). Before the procedure, all patients were managed as previously described [7]. The bronchoscope (BF XT 20 or BF P 40; Olympus Optical Co., Tokyo, Japan) was introduced into the endotracheal tube through a special adaptor (Double Swivel Connector; Medisize Co., Hillegom, the Netherlands) to reduce gas leakage. Loss of tidal volume was compensated by increasing the peak pressure up to $60 \mathrm{~cm} \mathrm{H}_{2} \mathrm{O}$. The bronchoscope was wedged in the affected lung segment identified by thoracic imaging. BAL was performed as reported by MARQUETTE et al. [11], the first $20 \mathrm{~mL}$ aliquot being discarded to avoid bacterial contamination. TBLB immediately followed BAL. The forceps (FB 35 C or FB-19C-1; Olympus Optical Co.) were advanced into the same lung segment as for BAL. The number of biopsies retrieved was determined by the operator. TBLB was executed, under fluoroscopic guidance, as described by O'BRIEN et al. [7], as was surveillance for pneumothorax. A pneumothorax occupying $>20 \%$ of the hemithorax was drained, otherwise it was monitored by repeated chest radiographs.

\section{Laboratory processing}

Whenever possible, one biopsy specimen was placed in sterile water for culture. BAL and TBLB samples were immediately transported to the microbiology laboratory. BAL specimens were processed for bacterial, fungal, viral and mycobacterial culture as the authors previously described [12]. TBLB samples were processed for bacterial and fungal culture. Total cell count was performed as reported elsewhere [13]. The other biopsies were placed in Bouin's fluid. All biopsy and autopsy specimens were prepared following standard practices [12].

\section{Data collection}

Data were collected from the medical records and from the bronchoscopy database, a prospectively maintained record of all fibreoscopies conducted in the department. The following variables were evaluated: age, sex, intensive care unit (ICU) admitting diagnosis, reason for the procedure, patient category, pre-BAL/TBLB physiological parameters (blood gases, haemodynamic status), coagulation status and use of prophylactic anticoagulants, ventilator settings and subsequent airway pressures (peak and plateau).

During the procedure, haemodynamic parameters and oxygen saturation were recorded every minute (Monitoring HP OmniCare M1165/66A; Hewlett Packard Company, Andover, MA, USA) in 32 patients. Blood gases at fractional concentration of oxygen in inspired gas $\left(F \mathrm{I}, \mathrm{O}_{2}\right) \quad 1$ were obtained immediately before the introduction and at the removal of the fibrescope in 33 patients.

The following post BAL/TBLB data were analysed: 1) physiological parameters and ventilator settings (after 2, 6, 24 and $48 \mathrm{~h}$ ); 2) procedure complications; 3) cultures (from BAL in all patients and from TBLB in 33 patients); and 4) modifications in patient management as a result of the BAL/ TBLB. Histological correlations between lung tissue obtained with TBLB or open-lung biopsy and/or autopsy were performed when available.
The following were considered procedure-related complications: significant bleeding $(\geqslant 30 \mathrm{~mL})$, pneumothorax, new pulmonary infection (according to the definitions used by O'BRIEN et al. [7]), death, increases in body temperature of $1{ }^{\circ} \mathrm{C}$ and $>38^{\circ} \mathrm{C}$ within $24 \mathrm{~h}$, severe hypotension (MAP $\leqslant 60 \mathrm{mmHg}$ ), bradycardia (heart rate (HR) $\leqslant 50$ beats $\left.\cdot \mathrm{min}^{-1}\right)$, tachycardia $\left(\mathrm{HR} \geqslant 150\right.$ beats $\left.\cdot \mathrm{min}^{-1}\right)$ or an arterial oxygen saturation of $<90 \%$ during the technique.

The patient's physician was free to modify treatment according to the BAL/TBLB results. The addition, withdrawal and lack of introduction (when a pre-procedure decision was cancelled due to the BAL/TBLB results) of a therapy were considered therapeutic modifications. Management changes were attributed to the BAL/TBLB procedure when the lung tissue biopsies yielded clinical information unobtainable without histological specimens (e.g. rejection in transplanted lung) and the results of the cultures provided new information that altered antibiotic therapy. The procedure was judged contributive when the results confirmed the suspected diagnosis even though treatment was not modified. Two authors (P.A. Bulpa and L. Mertens) reviewed the patients' data.

\section{Statistical analysis}

Numerical variables are expressed as mean \pm SD or median with interquartile ranges (IQR). A one-way analysis of variance for repeated measures was used to compare the various parameters at different time points and to detect any significant changes from baseline values. Blood gases before and immediately after bronchoscopy were compared by a paired t-test. Correlation of particular complications with categorical or continuous variables was assessed by Chisquared or Wilcoxon rank sum tests, respectively. All statistical tests were two-tailed. A p-value of $<0.05$ was considered as statistically significant.

\section{Results}

\section{Patient and procedure characteristics}

During the study period, 41 patients underwent combined BAL/TBLB, among whom 38 presented sufficient data to allow analysis. To facilitate the interpretation of results, patients were divided into two groups: immunocompetent $(\mathrm{n}=22$, group 1) and immunocompromised $(\mathrm{n}=16$, group 2$)$, with the latter including those receiving long-term treatment with $>10 \mathrm{mg}$ equivalent prednisone. In addition, within group 1 , patients with and without late-phase acute respiratory distress syndrome (ARDS, according to the definitions of the consensus conference criteria [14]) were analysed separately: groups $1 \mathrm{a}$ and $1 \mathrm{~b}$ respectively. All patients undergoing BAL/ TBLB had radiographical evidence of pulmonary infiltrate(s), which occurred before or during invasive mechanical ventilation. BAL/TBLB was performed at a median time of 10 days (range 0-35) after tracheal intubation.

Patient features are summarised in table 1. On admission, the Acute Physiology, Age, and Chronic Health Evaluation (APACHE) II score was $25 \pm 9$ and the Simplified Acute Physiology Score (SAPS) II was $48 \pm 16$. Because diagnosis was essential for appropriate therapy to be instituted, the procedure was performed in one patient with an aPTT of $58 \mathrm{~s}$ (limited bleeding $(35 \mathrm{~mL})$ was observed).

According to the protocol, to allow a good return of BAL fluid, positive end-expiratory pressure (PEEP) was maintained at $\leqslant 5 \mathrm{cmH}_{2} \mathrm{O}$, except in one case where oxygen 
Table 1.-Features of mechanically ventilated patients with unexplained pulmonary infiltrates

\section{Group 1a Group 1b Group 2}

\begin{tabular}{llcc}
\hline Subjects n & 11 & 11 & 16 \\
M:F & $7: 4$ & $6: 5$ & $10: 6$ \\
Hospital admitting diagnosis & & & \\
$\quad$ Surgical & 9 & 6 & 2 \\
$\quad$ Medical & 2 & 5 & 14 \\
ICU admitting diagnosis & & & \\
$\quad$ Sepsis/septic shock & 7 & 2 & 1 \\
ARF/pneumonia & 2 & 4 & 11 \\
$\quad$ Surgery & 2 & 5 & 1 \\
Other & & & \\
$\quad$ Febrile neutropenia & & & 1 \\
$\quad$ Haemorrhagic shock & & & 1 \\
$\quad$ Cardiac arrest & & & 1 \\
\hline
\end{tabular}

Data are presented as $\mathrm{n}$ unless otherwise stated. Group 1a: immunocompetent patients suffering from late-phase acute respiratory distress syndrome (ARDS); Group 1b: immunocompetent patients with unexplained infiltrate(s) but who did not fulfil ARDS criteria; Group 2: immunocompromised patients with unexplained pulmonary infiltrate(s). M: male; F: female; ICU: intensive care unit; ARF: acute respiratory failure. ": median age (interquartile range) 67 (51-71).

desaturation was observed when PEEP was $<10 \mathrm{cmH}_{2} \mathrm{O}$. Before the technique, $F \mathrm{I}, \mathrm{O}_{2}$ ranged from $0.26-1$ (median 0.49 ). Twelve patients required an $F \mathrm{I}, \mathrm{O}_{2}$ of $\geqslant 0.6$, seven of whom were receiving nitric oxide.

In 33 patients, blood gases at $F \mathrm{I}, \mathrm{O}_{2} 100 \%$ were analysed immediately before and after bronchoscopy. Arterial oxygen tension $\left(\mathrm{Pa}, \mathrm{O}_{2}\right)$ decreased from $262 \pm 121$ to $244 \pm 120 \mathrm{mmHg}$ $(\mathrm{p}=0.09)$. Carbon dioxide arterial tension $\left(\mathrm{Pa}, \mathrm{CO}_{2}\right)$ increased significantly from $40 \pm 7$ to $51 \pm 9 \mathrm{mmHg}(\mathrm{p}<0.001)$. As a consequence, $\mathrm{pH}$ decreased from $7.41 \pm 0.06$ to $7.32 \pm 0.07$ $(\mathrm{p}<0.001)$. Interestingly, $\mathrm{Pa}, \mathrm{CO}_{2}$ and $\mathrm{pH}$ returned to their preprocedure levels within $2 \mathrm{~h}$ in the 23 patients in whom blood gases were obtainable after 2, 6, 24 and $48 \mathrm{~h}$.

Respiratory frequency, tidal and minute ventilations, and peak and plateau pressures were stable between the preprocedure period and $2 \mathrm{~h}$ after the bronchoscopy. As per protocol, $F \mathrm{I}, \mathrm{O}_{2}$ was increased to 1 before and during the procedure, and then adjusted to maintain an oxygen saturation of $\geqslant 90 \%$; it took $6 \mathrm{~h}$ for levels to return to baseline values. The median duration of the procedure was 23 min (range 11-53).

\section{$B A L$ and $T B L B$ results and contribution to therapy}

A median of five (range 1-8; IQR 5-6) biopsies was performed per patient. With experience, the number of biopsies taken increased to a minimum of five. On two occasions at the beginning of the study, just one biopsy was taken. Based on the results of histopathology and/or TBLB culture, aetiological diagnosis was obtained in 24 of 38 cases $(63 \%$, table 2$)$, and, as the only positive test, contributed to specific diagnosis in 17 patients, i.e. nine out of 11 , three out of 11 and five out of 16 in groups $1 \mathrm{a}, 1 \mathrm{~b}$, and 2 , respectively. In noncontributive TBLB, histological diagnosis included diffuse alveolar damage, bronchial or pleural tissue, normal parenchyma and cryptogenic organising pneumonia. The number of TBLB specimens retrieved in patients with contributive histopathological diagnoses was not significantly different from the number obtained in patients without specific diagnoses.
The average amount of BAL fluid retrieved from the patients was $55 \pm 24 \mathrm{~mL}$ (range 15-95 mL). The median number of cells in the BAL fluid was $265 \mathrm{~mm}^{-3}$ (range $15-1,000 \mathrm{~mm}^{-3}$ ). There was no correlation between the differential cell count in the BAL fluid and a specific diagnosis. However, BAL yielded $11(29 \%)$ specific diagnoses and, as the only positive test, contributed to specific diagnosis in four cases (table 2). The therapeutic contributions of BAL/ TBLB are listed in table 2. In groups $1 \mathrm{a}, 1 \mathrm{~b}$ and 2, diagnosis was obtained in 11 of 11 , seven of 11 and 10 of 16 patients, respectively, and therapy changed in 11 of 11 , six of 11 and seven of 16 .

The performance of the procedure (combined BAL/TBLB or each separately), calculated as the ratio of the number of patients in whom the procedure contributed to therapy to the total number of patients studied, was $74 \%$ (28 out of 38 ) for BAL/TBLB, $29 \%$ (11 out of 38 ) for BAL, and 63\% (24 out of 38) for TBLB (fig. 1).

Three patients underwent OLB because the bronchoscopic procedure was inconclusive and autopsy examination was obtained in 10 cases. There was a good correlation between BAL/TBLB and tissue obtained at necropsy in four patients (confirmed diagnoses: invasive pulmonary aspergillosis (IPA) in two patients and emphysematous lesions in two). In three patients, no correlation could be found because BAL/TBLB yielded no diagnostic information (final diagnoses: lipoid pneumonia, usual interstitial pneumonia and IPA associated with some foci of bronchiolitis obliterans organising pneumonia). In the remaining patients, therapy was modified and subsequent treatment could have altered the autopsy findings since the delay between the two procedures exceeded 10 days.

\section{Complications}

No fatalities were attributable to the procedure. Some complications were procedure-related (table 3). Pneumothorax was always discovered during fluoroscopic guidance. The air leak was transient (median 1 day, range 1-12) and no persistent bronchopleural fistulas were observed. There was no significant correlation between the number of TBLB samples, the level of PEEP or peak and plateau pressures and the appearance of a pneumothorax $(\mathrm{p}>0.7)$.

Median platelet counts were significantly lower in patients with haemorrhage (72,000; IQR 35,250-159,000 thrombocytes $\cdot \mathrm{mm}^{-3}$ ) than in patients without bleeding $(187,500 ;$ IQR 100,500-301,750) $(\mathrm{p}=0.023)$. Although 27 patients received low molecular weight heparin for venous thromboembolism prophylaxis, there was no association between its use and the occurrence of haemorrhage.

MAP always remained $>60 \mathrm{mmHg}$, except in two patients in whom transient decreases were promptly corrected. No patient developed bradycardia or tachycardia during bronchoscopy.

During the procedure, three patients experienced temporary oxygen desaturation requiring the withdrawal of the fibrescope. No new pulmonary infection was procedurerelated. Thirteen transient episodes of fever occurred after the procedure.

\section{Discussion}

The results of this study show that, in mechanically ventilated patients with unexplained pulmonary infiltrates, combined BAL/TBLB is of diagnostic value. Indeed, diagnosing the aetiology of pulmonary infiltrates in these patients is often difficult and a common dilemma is whether to proceed with invasive diagnostic procedures. When infection has been excluded, specific therapy often requires analysis of 
Table 2. - Contribution of the combined bronchoalveolar lavage (BAL)/transbronchial lung biopsy (TBLB) procedure to the diagnosis and therapy of mechanically ventilated patients with unexplained pulmonary infiltrates

\begin{tabular}{|c|c|c|c|}
\hline & Group 1a & Group 1b & Group 2 \\
\hline $\begin{array}{l}\text { Subjects n } \\
\text { Diagnosis } \#\end{array}$ & 11 & 11 & 16 \\
\hline \multicolumn{4}{|l|}{ Diagnosis $^{\#}$} \\
\hline $\begin{array}{l}\text { Fibroproliferation } \\
\text { BOOP }\end{array}$ & $11(\mathrm{H})$ & & \\
\hline $\begin{array}{l}\text { BOOP } \\
\text { NSIP }\end{array}$ & & $2(\mathrm{H})$ & $2(\mathrm{H})$ \\
\hline $\begin{array}{l}\text { NSIP } \\
\text { IPA }\end{array}$ & & $1(\mathrm{H})$ & \\
\hline $\begin{array}{l}\text { IPA } \\
\text { Herpes }\end{array}$ & & & $3\left(1 \mathrm{H}, 1 \mathrm{H} / \mathrm{M}, 1 \mathrm{M}^{\top}\right)$ \\
\hline Herpes & & & $1(\mathrm{H})$ \\
\hline Capillary thrombosis & & & $1(\mathrm{H})$ \\
\hline Infection not confirmed & $1(\mathrm{M})$ & $1(\mathrm{M})$ & $2(\mathrm{H} / \mathrm{M})$ \\
\hline Infection & 1 C. albicans $\left(\mathrm{M}^{\top}\right)$ & $\begin{array}{c}1 \text { M. morganni }\left(\mathrm{M}^{\bullet}\right) \\
1 \text { Influenza A }(\mathrm{M})\end{array}$ & $1 \mathrm{CMV}(\mathrm{M})$ \\
\hline $\begin{array}{l}\text { Acute eosinophilic } \\
\text { pneumonia }\end{array}$ & & 1 (BAL cell count) & \\
\hline $\begin{array}{l}\text { Therapeutic } \\
\text { contribution }^{+}\end{array}$ & $\begin{array}{l}11 \text { TM (9 TBLB, } \\
2 \mathrm{BAL} / \mathrm{TBLB})\end{array}$ & $\begin{array}{c}6 \text { TM (3 TBLB, } 1 \\
\text { BAL/TBLB, } 2 \text { BAL) } \\
1 \text { TNM (BAL) }\end{array}$ & $\begin{array}{c}7 \text { TM (3 TBLB, } \\
3 \text { BAL/TBLB, } 1 \text { BAL) } \\
3 \text { TNM (2 TBLB, } \\
1 \text { BAL/TBLB })\end{array}$ \\
\hline \multirow{2}{*}{\multicolumn{4}{|c|}{ Applied therapy }} \\
\hline & & & \\
\hline Steroids & $11(\mathrm{H})$ & 4 ( $3 \mathrm{H}, 1 \mathrm{BAL}$ cell count $)$ & $2(\mathrm{H})$ \\
\hline Heparin & & & $1(\mathrm{H})$ \\
\hline AI & $1\left(\mathrm{M}^{\natural}\right)$ & $1\left(\mathrm{M}^{\natural}\right)$ & $2(1 \mathrm{H}, 1 \mathrm{M})$ \\
\hline AI not introduced & & & $1(\mathrm{H} / \mathrm{M})$ \\
\hline Stop AI & $1(\mathrm{M})$ & $1(\mathrm{M})$ & $1(\mathrm{H} / \mathrm{M})$ \\
\hline Withholding therapy ${ }^{f}$ & & & $1\left(\mathrm{M}^{\oplus}\right)$ \\
\hline Survival & $5 / 11$ & $5 / 11$ & $5 / 16$ \\
\hline
\end{tabular}

Data are presented as $\mathrm{n}$. Group 1a: immunocompetent patients suffering from late-phase acute respiratory distress syndrome (ARDS); Group 1b: immunocompetent patients with unexplained pulmonary infiltrate(s) but who did not fulfil ARDS criteria; Group 2: immunocompromised patients with unexplained pulmonary infiltrate(s). BOOP: bronchiolitis obliterans with organising pneumonia; NSIP: nonspecific interstitial pneumonia; IPA: invasive pulmonary aspergillosis; AI: anti-infective agent; H: histology; M: microbiology from BAL; C. albicans: Candida albicans; TM: therapy modified; M. morganii: Morganella morganii; TNM: therapy not modified; CMV: cytomegalovirus. ${ }^{\#}$ : more than one diagnosis may be obtained per patient; ": microbiology with the same pathogen retrieved from BAL and TBLB; ${ }^{+}$: the procedure was contributive, although treatment was not modified after diagnosis of BOOP (spontaneously favourable evolution), because the need for antifungal therapy was confirmed or infection was not confirmed; $\$$ : more than one therapy may have been applied per patient; ${ }^{f}$ : after confirmation of an invasive pulmonary aspergillosis.

pulmonary tissue. OLB is the procedure of choice with a diagnostic usefulness of 46-100\% [2-6], depending on specific diagnostic criteria; a higher yield is often reported in ARDS patients [5]. However, some authors have proposed TBLB instead of OLB [7-9]. The diagnostic yield from these two techniques is indeed quite similar. By pooling the previous studies on TBLB $[7-9,15,16]$, the authors observe that specific diagnoses were obtained in $\sim 40 \%$ of cases (leading to treatment changes in $\sim 45 \%$ ). However, the bronchoscopic yield could be enhanced by combining it with BAL $[8,9]$. Indeed, the current study shows that the performance of the combined BAL/TBLB procedure reached $74 \%$, while the yields of TBLB and BAL alone were $63 \%$ and $29 \%$, respectively. The procedure was contributive in 28 patients (74\%): therapy was modified in $24(63 \%)$ and diagnosis was confirmed (although without management changes) in four $(11 \%)$. In each group, BAL/TBLB was profitable: diagnosis was obtained in $100,64 \%$ and $63 \%$ of cases, and therapy was changed in 11 of 11 , six of 11 and seven of 16 patients, in groups $1 \mathrm{a}, 1 \mathrm{~b}$ and 2 , respectively.

Although the combined BAL/TBLB is of diagnostic value, some complications may occur, as during TBLB alone [7-9] oxygen desaturation, pneumothorax, bleeding and hypotension were noted, but no life-threatening complications were encountered. Following is a discussion of each complication in turn. First, blood gases were obtainable in 33 patients just before and immediately after the bronchoscopy. The results showed moderate but not significant reductions in $\mathrm{Pa}, \mathrm{O}_{2}$. Several studies have evaluated oxygenation parameters in mechanically ventilated patients after BAL [17-23]. However, results are conflicting, as some authors reported a significant decrease in oxygenation, while others noted no such effects when different ventilator settings were adapted and $F \mathrm{I}, \mathrm{O}_{2}$ was increased during the bronchoscopy. O'BRIEN et al. . [7] found no differences in $\mathrm{Pa}, \mathrm{O}_{2}$ obtained after TBLB compared with baseline values. Moreover, they observed no differences between the two measurements in $\mathrm{pH}$ or $\mathrm{Pa}, \mathrm{CO}_{2}$. On the contrary, the authors noted a highly significant decrease in $\mathrm{pH}$ and an increase in $\mathrm{Pa}, \mathrm{CO}_{2}$ from the beginning to the end of the procedure. Interestingly, these modifications were transient, as baseline values were regained within $2 \mathrm{~h}$. Secondly, even in the presence of positive pressure ventilation, the rate of pneumothorax requiring drainage was $16 \%$, similar to the mean of $12 \%(0-15 \%)$ reported in previous studies [7-9, 15, 16]. No persistent bronchopleural fistulas were encountered. Thirdly, in the authors' experience, $11 \%$ of patients developed moderate and self-limiting haemorrhage, but none experienced severe bleeding, as already mentioned in the literature [7, 8]. Although the authors could not find a correlation between the use of prophylactic doses of low molecular weight heparin and the risk of bleeding, platelet counts were significantly lower in patients with haemorrhage. Finally, a 


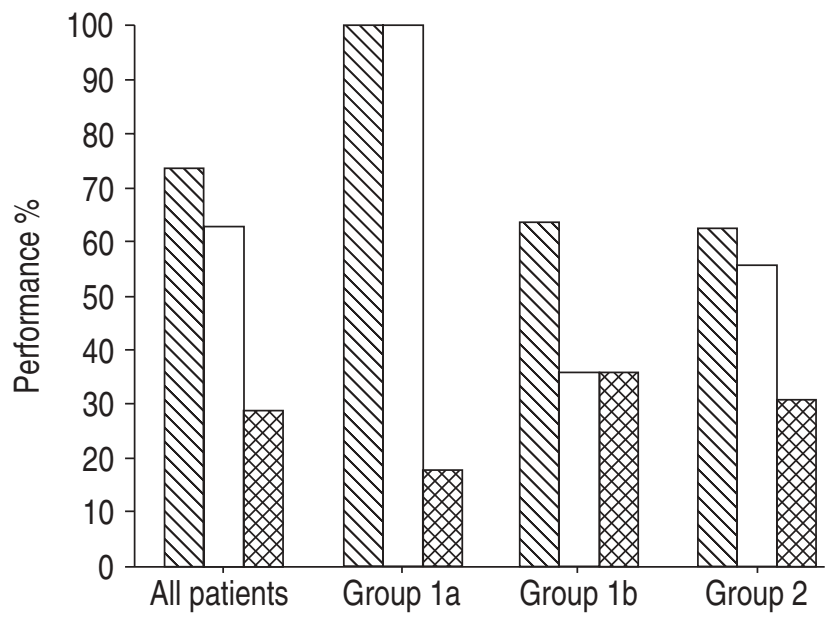

Fig. 1.-Performance of the combined bronchoalveolar lavage/ transbronchial lung biopsy (BAL/TBLB), TBLB and BAL procedure in all patients and in each group, expressed as percentages. The performance of the combined procedure (or BAL and TBLB alone) was calculated as the ratio of the number of patients in whom the procedure contributed to therapy to the total number of patients studied. Group 1a: immunocompetent patients suffering from latephase acute respiratory distress syndrome (ARDS); Group 1b: immunocompetent patients with unexplained pulmonary infiltrate(s) but who did not fulfil ARDS criteria; Group 2: immunocompromised patients with unexplained pulmonary infiltrate(s). $\mathbb{Q}$ : BAL/TBLB; $\square$ : TBLB; $\mathbf{E A L}$.

Table 3.-Complications ${ }^{\#}$ of the bronchoalveolar lavage/ transbronchial lung biopsy procedure in mechanically ventilated patients with unexplained pulmonary infiltrates

\begin{tabular}{lccc}
\hline & Group 1a & Group 1b & Group 2 \\
\hline $\begin{array}{l}\text { Subjects n } \\
\text { Pneumothorax }\end{array} \quad 11$ & 11 & 16 \\
$\quad$ Requiring drainage & 3 & 1 & 2 \\
$\quad$ Not requiring drainage & 1 & 1 & 2 \\
Bleeding & 1 & 1 & 3 \\
Hypotension & 1 & 1 & 1 \\
\hline Oxygen saturation $<90 \%$ & & & \\
\hline
\end{tabular}

Data are presented as n. Group 1a: immunocompetent patients suffering from late-phase acute respiratory distress syndrome (ARDS); Group 1b: immunocompetent patients with unexplained pulmonary infiltrate(s) but who did not fulfil ARDS criteria; Group 2: immunocompromised patients with unexplained pulmonary infiltrate(s). ${ }^{\text {\# }}$ : more than one complication may have occurred per patient; ' : bleeding (30-35 mL) was selflimiting or responded well to the instillation of $2 \mathrm{mg}$ of epinephrine $(n=1)$.

decrease in MAP occurred in two patients, but MAP returned to $>60 \mathrm{mmHg}$ at the end of the procedure. This finding is similar to that reported by O'BRIEN et al. [7].

OLB, the diagnostic tool of choice in mechanically ventilated patients with unexplained infiltrates, also carries the risk of complications. First, during OLB, FLABOURIS and MYBURGH [2] reported intraoperative oxygen saturations of $<90 \%$ in $17 \%$ of their patients versus $8 \%$ oxygen desaturation documented during BAL/TBLB. Secondly, chest tubes are always left in place after OLB and some cases of persistent bronchopleural fistula have been described [2-5, 24], as well as instances of perioperative mortality $[2,6]$. Thirdly, after OLB, bleeding was also observed in $1-7 \%$ of patients $[2,3,5,6$,
24-27], requiring reoperation in some cases, and one death was directly attributable to uncontrolled haemorrhage [28]. Finally, hypotension was encountered at the same rate after OLB compared to BAL/TBLB $[2,4,25]$. While no deaths have been directly related to fibreoptic procedures (BAL/TBLB or TBLB alone), OLB operative mortality rates of $\leqslant 12 \%[2,26$, $27,29]$ have been reported. Based on the results of the present study, the yield and tolerance of BAL/TBLB are comparable to those of OLB. However, the BAL/TBLB procedure carries two potential advantages: 1) repeated samplings of BAL and TBLB can be performed, which is very difficult with OLB; and 2) BAL/TBLB can be performed at the bedside. Although OLB can also be made at the bedside in the ICU under strict conditions [5, 24], patient transfer to the operating room is preferable [5].

The appropriateness of performing BAL/TBLB in one procedure rather than BAL followed by TBLB if no diagnosis is obtained, could be questioned. However, the patients included in this study were critically ill and it was crucial that a correct diagnosis was obtained as quickly as possible. The combined BAL/TBLB procedure may save time. Indeed, if BAL alone is performed, it may take $\leqslant 5$ days for all the results to be available. TBLB would then be performed, needing another 2-3 days for the results. Performing BAL and TBLB together may save 2-5 days. In addition, the combined procedure reduces the time needed to achieve a diagnosis and hence perhaps ICU costs.

The indication to perform the combined BAL/TBLB procedure was that of TBLB, i.e. the need for tissue examination when it was considered necessary for a correct diagnosis. The addition of BAL to the procedure, despite its apparent low yield, may be useful for several reasons. First, in patients suffering from undetermined pulmonary infiltrate(s), some diseases are better diagnosed with $\mathrm{BAL}$ (e.g. acute eosinophilic pneumonia, viral pneumonia), whereas TBLB often shows nonspecific changes. Secondly, in ARDS patients, BAL can exclude infection when the administration of steroids is being considered [30, 31]. Thirdly, in immunocompromised hosts, the results of both BAL and TBLB aid the detection of pulmonary infection [32]

In patients with late ARDS, the morbidity related to the procedure was high; four of $11(36.4 \%)$ patients developed pneumothorax. In addition, therapy resulting from biopsy results could be predicted, i.e. steroids were always initiated due to the presence of fibroproliferation. Therefore, BAL/ TBLB cannot be recommended in such patients. This is in concordance with some authors who have suggested that in patients with late ARDS who fail to improve and when concurrent pulmonary infection is excluded, steroid therapy should be introduced without histological confirmation [33].

In conclusion, combined bronchoalveolar lavage/transbronchial lung biopsy performed at the bedside by a skilled pulmonologist is valuable in mechanically ventilated patients with unexplained pulmonary infiltrate(s), but not in patients with late acute respiratory distress syndrome. Although complications are to be expected, the procedure represents an alternative to open lung biopsy. Nonetheless, open lung biopsy remains an important diagnostic tool, especially after a nondiagnostic bronchoalveolar lavage/transbronchial lung biopsy procedure.

Acknowledgements. The authors thank P. Jolliet for reviewing the manuscript.

\section{References}

1. de Jaeger A, Litalien C, Lacroix J, Guertin M-C, InfanteRivard C. Protected specimen brush or bronchoalveolar lavage to diagnose bacterial nosocomial pneumonia in 
ventilated adults: A meta-analysis. Crit Care Med 1999; 27: 2548-2560.

2. Flabouris A, Myburgh J. The utility of open lung biopsy in patients requiring mechanical ventilation. Chest 1999; 115: 811-817.

3. Nelems JM, Cooper JD, Henderson RD, Peng T, Phillips MJ. Emergency open lung biopsy. Ann Thorac Surg 1976; 22: 260-264.

4. Canver CC, Mentzer RM. The role of open lung biopsy in early and late survival of ventilator-dependent patients with diffuse idiopathic lung disease. J Cardiovasc Surg 1994; 35: 151-155.

5. Papazian L, Thomas $\mathrm{P}$, Bregeon $\mathrm{F}$, et al. Open-lung biopsy in patients with acute respiratory distress syndrome. Anesthesiology 1998; 88: 935-944.

6. Warner DO, Warner MA, Divertie MB. Open lung biopsy in patients with diffuse pulmonary infiltrates and acute respiratory failure. Am Rev Respir Dis 1988; 137: 90-94.

7. O'Brien JD, Ettinger NA, Shevlin D, Kollef MH. Safety and yield of transbronchial biopsy in mechanically ventilated patients. Crit Care Med 1997; 25: 440-446.

8. Papin TA, Grum CM, Weg JG. Transbronchial biopsy during mechanical ventilation. Chest 1986; 89: 168-170.

9. Pincus PS, Kallenbach JM, Hurwitz MD, et al. Transbronchial biopsy during mechanical ventilation. Crit Care Med 1987; 15: 1136-1139.

10. Dombret MC. Endoscopie bronchique en réanimation. Technique et indications de 1'endoscopie bronchique chez le patient ventilé artificiellement. Rev Mal Respir 1999; 16: 3S91-3S95.

11. Marquette $\mathrm{CH}$, Copin M-C, Wallet F, et al. Diagnostic tests for pneumonia in ventilated patients: prospective evaluation of diagnostic accuracy using histology as a diagnostic gold standard. Am J Respir Crit Care Med 1995; 151: 1878-1888.

12. Bulpa PA, Dive AM, Garrino MG, et al. Chronic obstructive pulmonary disease patients with invasive pulmonary aspergillosis: benefits of intensive care? Intensive Care Med 2001; 27: 59-67.

13. Sibille Y, Martinot JB, Staquet P, Delaunois L, Chatelain B, Delacroix DL. Antiproteases are increased in bronchoalveolar lavage in interstitial lung disease. Eur Respir J 1988; 1: 498-504.

14. Bernard GR, Artigas A, Brigham KL, et al. The AmericanEuropean Consensus Conference on ARDS. Definitions, mechanisms, relevant outcomes and clinical trial coordination. Am J Respir Crit Care Med 1994; 149: 814-824.

15. Turner JS, Willcox PA, Hayhurst MD, Potgieter PD. Fiberoptic bronchoscopy in the intensive care unit. A prospective study of 147 procedures in 107 patients. Crit Care Med 1994; 22: 259-264.

16. Martin C, Papazian L, Payan M-J, Saux P, Gouin F. Pulmonary fibrosis correlates with outcome in adult respiratory distress syndrome. A study in mechanically ventilated patients. Chest 1995; 107: 196-200.

17. Montravers P, Gauzit R, Dombret MC, Blanchet F, Desmonts JM. Cardiopulmonary effects of bronchoalveolar lavage in critically ill patients. Chest 1993; 104: 1541-1547.
18. Papazian L, Colt HG, Scemama F, Martin C, Gouin F Effects of consecutive protected specimen brushing and bronchoalveolar lavage on gas exchange and hemodynamics in ventilated patients. Chest 1993; 104: 1548-1552.

19. Guerra LF, Baughman RP. Use of bronchoalveolar lavage to diagnose bacterial pneumonia in mechanically ventilated patients. Crit Care Med 1990; 18: 169-173.

20. Bauer TT, Torres A, Ewig S, et al. Effects of bronchoalveolar lavage volume on arterial oxygenation in mechanically ventilated patients with pneumonia. Intensive Care Med 2001; 27: 384-393.

21. Ricou B, Grandin S, Nicod L, Thorens JB, Suter PM. Adult and paediatric size bronchoscopes for bronchoalveolar lavage in mechanically ventilated patients: yield and side effects. Thorax 1995; 50: 290-293.

22. Hertz MI, Woodward ME, Gross CR, Swart M, Marcy TW, Bitterman PB. Safety of bronchoalveolar lavage in the critically ill, mechanically ventilated patient. Crit Care Med 1991; 19: 1526-1532.

23. Steinberg KP, Mitchell DR, Maunder RJ, Milberg JA, Whitcomb ME, Hudson LD. Safety of bronchoalveolar lavage in patients with adult respiratory distress syndrome. Am Rev Respir Dis 1993; 148: 556-561.

24. Hill JD, Ratliff JL, Parrott JC, et al. Pulmonary pathology in acute respiratory insufficiency: Lung biopsy as a diagnostic tool. J Thorac Cardiovasc Surg 1976; 71: 64-71.

25. Cheson BD, Samlowski WE, Tang TT, Spruance SL. Value of open-lung biopsy in 87 immunocompromised patients with pulmonary infiltrates. Cancer 1985; 55: 453-459.

26. Ray JF, Lawton BR, Myers WO, et al. Open pulmonary biopsy. Nineteen-year experience with 416 consecutive operations. Chest 1976; 69: 43-47.

27. White DA, Wong PW, Downey R. The utility of open lung biopsy in patients with hematologic malignancies. Am J Respir Crit Care Med 2000; 161: 723-729.

28. Kramer MR, Berkman N, Mintz B, Godfrey S, Saute M, Amir G. The role of open lung biopsy in the management and outcome of patients with diffuse lung disease. Ann Thorac Surg 1998; 65: 198-202.

29. Satterfield JR, McLaughlin JS. Open lung biopsy in diagnosing pulmonary infiltrates in immunosuppressed patients. Ann Thorac Surg 1979; 28: 359-362.

30. Meduri GU, Chin AJ, Leeper KV, et al. Corticosteroid rescue treatment of progressive fibroproliferation in late ARDS. Patterns of response and predictors of outcome. Chest 1994; 105: 1516-1527.

31. Meduri GU, Headley AS, Golden E, et al. Effect of prolonged methylprednisolone therapy in unresolving acute respiratory distress syndrome. A randomized controlled trial. JAMA 1998; 280: 159-165.

32. Broaddus C, Dake MD, Stulbarg MS, et al. Bronchoalveolar lavage and transbronchial biopsy for the diagnosis of pulmonary infections in the acquired immunodeficiency syndrome. Ann Intern Med 1985; 102: 747-752.

33. Meduri GU. Pulmonary fibroproliferation and death in patients with late ARDS. Chest 1995; 107: 5-6. 